\title{
The influence of hyperthyroidism in the electrophysiological properties of the atrial muscle in paroxysmal atrial fibrillation
}

Volume 6 Issue 3 - 2016

\section{Editorial}

Paroxysmal atrial fibrillation (PAF) is a common arrhythmia frequently seen in the clinical setting, and is well known to be associated with various pathological cardiac entities. ${ }^{1-5}$ These cardiac conditions include coronary heart disease, cardiomyopathy, pericardial disease, valvular heart disease, arterial hypertension, congestive heart failure, Wolff-Parkinson-White syndrome, and sinus node dysfunction. ${ }^{6-9}$ $\mathrm{PAF}$ is also associated with certain non-cardiac conditions, namely, aging, autonomic tones, thyroid function, acute alcohol intoxication, metabolic or electrolyte disturbances, and drugs, are also affecting initiation, maintenance, and termination of PAF. ${ }^{6,7}$ On the other hand, lone or idiopathic PAF has no identifiable underlying cause, and can occur any time for no apparent reason. ${ }^{10,11}$ Although these underlying causes may modify the electrophysiological properties of the atrium, there has been little information on the relationship between the atrial electrophysiological properties and predisposing conditions for PAF.

When a premature atrial depolarization encounters a period of incomplete recovery of excitability its conduction velocity diminishes. The conduction velocity and the effective refractory period (ERP) are the determinants in the genesis of reentrant arrhythmias according to the wavelength theory. ${ }^{12-14}$ The wavelength is calculated by multiplying the refractory period by conduction velocity, and it is considered as the distance traveled by the depolarization wave during the duration of refractoriness. If the atrial wavelength is long, reentry may not be maintained and the episode of PAF may terminate spontaneously. On the other hand, if the atrial wavelength is relatively short because of either a short refractory period, depressed conduction, or both, then a greater number of wave fronts can circulate through the atrium and atrial fibrillation may be sustained. Therefore, prolonged atrial conduction delay and/or shortened ERP could be expected to increase the propensity to develop episodes of PAF. ${ }^{12-14}$ The atrial vulnerability of the atrial myocardium in patients with PAF can be easily exposed in the electrophysiology laboratory. Abnormal responses of the atrial muscle can be elicited by programmed atrial stimulation during the electrophysiological study. ${ }^{15-18}$ Certain parameters of atrial vulnerability, namely, repetitive atrial firing, fragmented atrial activity, and intraatrial conduction delay (IACD) can be induced by atrial stimulation. These electrophysiological parameters of atrial vulnerability are more frequently induced in patients with PAF than in those patients without it..$^{1-5}$

Shorter atrial ERP has been also shown to be of electrophysiological significance in the genesis of PAF. On the other hand, the slowing in conduction of the atrial impulses may set the background for reentry to occur. ${ }^{1-5}$ Although an increase of $20 \mathrm{~ms}$ or more in the atrial conduction time in response to early extra-stimuli appears to be a physiological response of the normal atrium, patients with PAF show longer IACD zones and maximum IACDs than control subjects

\author{
Osmar Antonio Centurion, ${ }^{1,2}$ Shojiro \\ Isomoto ${ }^{1,2}$ \\ 'Department of Health Sciences? Investigation, Sanatorio \\ Metropolitano, Fernando de la Mora, Paraguay \\ ${ }^{2}$ Cardiology Division, First Department of Internal Medicine, \\ Clinic Hospital, Asunci
}

\begin{abstract}
Correspondence: Osmar Antonio Centurión, Professor of Medicine, Asuncion National University, Department of Health Sciences $\square$ Investigation, Sanatorio Metropolitano, Teniente Ettiene $215 \mathrm{c} /$ Ruta Mariscal Estigarribia, Fernando de la Mora, Paraguay, Tel 595-2I-498200, Fax 595-2I-205630, Email osmarcenturion@hotmail.com
\end{abstract}

Received: August 16,2016 | Published: August 18, 2016

without atrial arrhythmias. ${ }^{15-18}$ Thus, the IACD zone and maximum IACD are believed to be good indices of a tendency to develop AF. We have previously shown that these indices of atrial vulnerability were greater in patients with hyperthyroidism and PAF than in control subjects..$^{19,20}$ The greater atrial IACD and shorter atrial ERP resulted in shortening of the atrial wavelength, which predisposed to development of PAF. ${ }^{19-22}$ The mean atrial ERP in patients with hyperthyroidism $(187 \pm 7 \mathrm{~ms})$ was significantly shorter than that of controls $(215 \pm 29 \mathrm{~ms}, \mathrm{p}<0.01)$. The mean IACD zone in patients with hyperthyroidism $(63 \pm 57 \mathrm{~ms})$ was significantly greater than that of controls $(34 \pm 22 \mathrm{~ms})(\mathrm{p}<0.01) .{ }^{19}$ The mean maximum IACD in patients with hyperthyroidism $(64 \pm 37 \mathrm{msec})$ was also significantly greater than that of controls $(43 \pm 20 \mathrm{msec})(\mathrm{p}<0.01) .{ }^{19}$ Therefore, the increase of atrial IACD and the shortening of atrial ERP may contribute to develop PAF in patients with hyperthyroidism. With atrial endocardial mapping, we have previously reported a significantly greater extension of abnormal endocardial electrograms within the right atrium during sinus rhythm in patients with PAF. ${ }^{1-5}$ These abnormal atrial electrograms were believed to reflect areas of altered anatomy with fragmented, anisotropic, and slow conduction that renders patients with this electrophysiological abnormality vulnerable to develop AF. We have also showed that the area of diseased atrial muscle in the PAF patients with sinus node dysfunction was more extensive than in those without. ${ }^{1}$ In clinical studies, the duration of the monophasic action potential has been suggested to predict recurrence of AF after electrical cardioversion. ${ }^{23-25}$ Patients with persistently short monophasic action potential duration during sinus rhythm had a higher incidence of recurrent AF than patients with normal action potential duration. ${ }^{23-27}$ Therefore, any condition which shortens atrial ERP and action potential duration will be arrhythmogenic. Previous experimental studies suggested that changes in the thyroid state could modulate the repolarization and duration of the cardiac 
action potential. ${ }^{24,25}$ Thus, a shortening of the atrial ERP is expected to increase the propensity for PAF in patients with hyperthyroidism despite having or not an organic substrate in the atrial muscle.

Because the atrial ERP was shorter in patients with hyperthyroidism than in controls, earlier atrial premature beats with coupling intervals close to their shortened atrial ERP could facilitate atrial IACD.$^{19}$ In patients with hyperthyroidism, shortening of the atrial wavelength due to a slow atrial conduction velocity with short atrial ERP seems to predispose to development of intra-atrial reentry and, thus, clinical episodes of PAF.

\section{Acknowledgments}

None.

\section{Conflicts of interest}

Author declares there are no conflicts of interest.

\section{Funding}

None.

\section{References}

1. Centurion OA, Fukatani M, Konoe A, et al. Different distribution of abnormal endocardial electrograms within the right atrium in patients with sick sinus syndrome. Br Heart J. 1992;68(6):596-600.

2. Centurion OA, Isomoto S, Fukatani M, et al. Relationship between atrial conduction defects and fractionated atrial endocardial electrograms in patients with sick sinus syndrome. Pace. 1993;16(10):2022-2033.

3. Centurion OA, Shimizu A, Isomoto S, et al. Repetitive atrial firing and fragmented atrial activity elicited by extrastimuli in the sick sinus syndrome with and without abnormal atrial electrograms. Am J Med Sci. 1994;307(4):247-254.

4. Centurion OA, Isomoto S, Shimizu A, et al. The effects of aging on atrial endocardial electrograms in patients with paroxysmal atrial fibrillation. Clin Cardiol. 2003;26(9):435-438.

5. Centurión OA, Shimizu A, Isomoto S, et al. Influence of advancing age on fractionated right atrial endocardial electrograms. Am J Cardiol . 2005;96(2):239-242.

6. Kannel WB, Abbott RD, Savage DD, et al. Epidemiologic features of chronic atrial fibrillation: the Framingham study. $N$ Engl J Med . 1982;306(17):1018-1022.

7. Wyndham CRC, Amat y Leon F, Denes P, et al. Effects of cycle length on atrial vulnerability. Circulation. 1977;55(2):260-267.

8. Shimizu A, Fukatani M, Tanigawa M, et al. Intra-atrial conduction delay and fragmented atrial activity in patients with paroxysmal atrial fibrillation. Jpn Circ J. 1989;53(9):1023-1030.

9. Shimizu A, Centurion OA. Electrophysiological properties of the human atrium in atrial fibrillation. Cardio vasc Res. 2002;54:302-314.

10. Centurión OA, Isomoto S, Shimizu A. Electrophysiological changes of the atrium in patients with lone paroxysmal atrial fibrillation. $J$ Atrial Fib. 2010;3(1):3-9.

11. Centurión OA, Konoe A, Isomoto S, et al. Possible role of supernormal atrial conduction in the genesis of atrial fibrillation in patients with idiopathic paroxismal atrial fibrillation. Chest. 1994;106(3):842-847.
12. Cosio FG, Palacios J, Vidal JM, et al. Electrophysiologic studies in atrial fibrillation: Slow conduction of premature impulses: a possible manifestation of the background for reentry. Am J Cardiol. 1983;51(1):122-130.

13. Smeets JL, Allessie MA, Lammers WJ, et al. The wavelength of the cardiac impulse and reentrant arrhythmias in isolated rabbit atrium. The role of heart rate, autonomic transmitters, temperature and potassium. Circ Res . 1986;58(1):96-108.

14. Rensma PL, Allessie MA, Lammers WJ, et al. Length of excitation wave and susceptibility to reentrant atrial arrhythmias in normal conscious dogs. Circ Res. 1988;62(2):395-410.

15. Centurión OA, Shimizu A, Isomoto S, et al. Mechanisms for the genesis of paroxysmal atrial fibrillation in the Wolff- Parkinson-White syndrome: Intrinsic atrial muscle vulnerability vs. electrophysiological properties of the accessory pathway. Europace. 2008;10(3):294-302.

16. Centurión OA. Clinical implications of the $\mathrm{P}$ wave duration and dispersion: Relationship between atrial conduction defects and abnormally prolonged atrial endocardial electrograms. Int J Cardiol . 2009;134(1):6-8.

17. Centurion OA. Atrial fibrillation complicating congestive heart failure: Electrophysiological aspects and its deleterious effect on cardiac resynchronization therapy. J Atrial Fib. 2009;1(7):417-429.

18. Centurión OA. The Influence of Atrial Fibrillation on Cardiac Resynchronization Therapy. J Cardiol Curr Res. 2014;1(2):00008.

19. IsomotoS, Centurión OA, Shibata R, et al. Patients with paroxysmal atrial fibrillation exhibit an electrophysiological diversity of the atrium in conjunction with their complication status. Rev Soc Parag Cardiol . 2004;2:118-123.

20. Isomoto S, Centurión OA, Shibata R, et al. The effects of aging on the refractoriness and conduction of the atrium in patients with lone paroxysmal atrial fibrillation revealed with programmed atrial stimulation. Rev Soc Parag Cardiol . 2005;3:25-30.

21. Konoe A, Fukatani M, Tanigawa M, et al. Electrophysiological abnormalities of the atrial muscle in patients with manifest WolffParkinson-White syndrome associated with paroxysmal atrial fibrillation. Pacing Clin Electrophysiol. 1992;15(7):1040-1052.

22. Tanigawa M, Fukatani M, Konoe A, et al. Prolonged and fractionated right atrial electrograms during sinus rhythm in patients with paroxysmal atrial fibrillation and sick sinus node syndrome. J Am Coll Cardiol. 1991;17(2):403-408.

23. Cotoi S, Gavrilescu S, Pap T, et al. The prognostic value of right atrium monophasic action potential after conversion of atrial fibrillation. Eur $J$ Clin Invest. 1972;2:472-474.

24. Freedberg AS, Papp JG, Vaughan-Williams EM. The effect of altered thyroid state on atrial intracellular potentials. J Physiol. 1970;207(2):357-369.

25. Doohan MM, Hool LC, Rasmussen HH. Thyroid status and Na+-K+ pump current, intracellular sodium, and action potential duration in rabbit heart. Am J Physiol. 1995;268(5 Pt 2):H1838-H1846.

26. Isomoto S, Fukatani M, Konoe A, et al. The influence of advancing age on the electrophysiological changes of the atrial muscle induced by programmed atrial stimulation. Jpn Circ J. 1992;56(8):776-782.

27. Page RL, Wilkinson WE, Clair WK, et al. Asymptomatic arrhythmias in patients with symptomatic paroxysmal atrial fibrillation and paroxysmal supraventricular tachycardia. Circulation. 1994;89(1):224-227. 